\title{
Lições extraídas de uma experimentação estética sobre a relação do estudante de enfermagem com a pessoa em sofrimento psíquico
}

RESUMO ( Objetivo: analisar as emoções do estudante de enfermagem diante da iminência do estabelecimento da relação terapêutica com o usuário do Centro de Atenção Psicossocial (CAPS). Método: Trata-se de uma pesquisa qualitativa, de abordagem sociopoética, desenvolvida com 21 acadêmicos do $6^{\circ}$ período do Curso de Graduação em Enfermagem de uma universidade pública. Resultados: Foram relatadas diversas sensações, entre as quais: felicidade, tristeza, medo, surpresa, raiva e nojo, além de uma ambivalência de sensações. Por vezes, esta ambiguidade se fez patente e foi nítida a dificuldade de relatar e descrever as emoções e sentimentos na forma escrita, aparecendo melhor o que o corpo fala, e se apresenta de maneira marcante para expressar conteúdos velados dentro de si mesmo. Conclusão: Todos os participantes foram afetados pelos objetos contidos nas caixas, o que demonstrou grande necessidade e urgência para falarem sobre suas próprias afetações e sentimentos. Palavras-chaves: Saúde Mental; Emoções; Educação em Enfermagem.

\begin{abstract}
Objective: Analyze the emotions of nursing students facing the imminence of establishing a therapeutic relationship with the user of the Psychosocial Care Center (CAPS). Method: This is a qualitative research with a sociopoetic approach, developed with 21 students from the 6th period of the Nursing Undergraduate Course of a public university. Results: Several sensations were reported, including happiness, sadness, fear, surprise, anger and disgust, as well as an ambivalence of sensations. At times, this ambiguity was evident and the difficulty of reporting and describing the emotions and feelings in written form was clearer, better appearing what the body speaks, and is presented in a remarkable way to express veiled contents within itself. Conclusion: All participants were affected by the objects contained in the boxes, which showed great need and urgency to talk about their own affects and feelings.
\end{abstract}

Keywords: Mental Health; Emotions; Nursing Education.

RESUMEN | Objetivo: analizar las emociones de los estudiantes de enfermería ante la inminencia de establecer una relación terapéutica con el usuario del Centro de Atención Psicosocial (CAPS). Método: Esta es una investigación cualitativa con enfoque sociopoético, desarrollada con 21 estudiantes del sexto período del Curso de Pregrado en Enfermería de una universidad pública. Resultados: Se informaron varias sensaciones, entre ellas: felicidad, tristeza, miedo, sorpresa, enojo y asco, así como una ambivalencia de sensaciones. A veces, esta ambigüedad era evidente y estaba clara la dificultad de informar y describir las emociones y sentimientos en forma escrita, apareciendo mejor lo que el cuerpo habla, y se presenta de una manera notable para expresar contenidos velados dentro de sí mismo. Conclusión: Todos los participantes fueron afectados por los objetos contenidos en las cajas, que mostraron una gran necesidad y urgencia de hablar sobre sus propios afectos y sentimientos.

Descriptores: Salud Mental; Emociones; Educación de Enfermería.

\section{Raquel Tavares Brito Fernandes}

Mestranda do Programa Acadêmico em Ciências do Cuidado em Saúde (PACCS), Universidade Federal Fluminense (UFF).

\section{Claudia Mara de Melo Tavares}

Doutora em Enfermagem, Professora Titular do Programa Acadêmico em Ciências do Cuidado em Saúde (PACCS), Universidade Federal Fluminense.

\section{Paulo Cesar Toledo de Almeida}

Mestre em Psicologia Social. Professor Assistente da PRICHSA, Universidade de Vassouras.

\section{Letycia Sardinha Peixoto Manhães}

Doutoranda do Programa Acadêmico em Ciências do Cuidado em Saúde (PACCS).

\section{Marcela Pimenta Muniz}

Doutora em Enfermagem, Professora do Departamento de Enfermagem MaternoInfantil e Psiquiátrica (MEP), Universidade Federal Fluminense (UFF).

\section{Rafael Rodrigues Polakiewicz}

Doutorando em ciências do cuidado em saúde. Professor Enfermagem em saúde coletiva -UFF.

Recebido em: 22/07/2019

Aprovado em: 29/07/2019
INTRODUÇÃ̃O

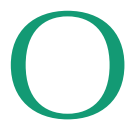

atual modelo de cuidar em saúde mental, orientado pela perspectiva do cuidado ampliado e operacionalizado por meio do projeto terapêutico singular (PTS), exige do enfermeiro grande capacidade de intenso diálogo com a equipe interdisciplinar e demais atores envolvidos no território do usuário dos serviços de saúde mental. O modo de Atenção Psicossocial requer operacionalização de ações de cuidado na comunidade, no espaço habitado pelas pessoas, de forma horizontal e cidadã, utilizando-se as mais variadas tecnologias de inclusão.

A convivência dentro de um cenário 
em constante transformação começou a colocar o enfermeiro de saúde mental diante de novos e importantes desafios, exigindo que se fizesse uma análise crítica dos saberes que fundamentavam sua prática profissional(1).

Tradicionalmente, o ensino de enfermagem psiquiátrica é pautado na disciplina, controle dos sintomas e espaços de enclausuramento da doença mental. No entanto, com a mudança de modelo assistencial, é imperioso realizar transformações no ensino para atender às exigências de mudança da ação profissional do enfermeiro. Além disso, é necessário pensar o campo da saúde mental e atenção psicossocial não como um sistema fechado, mas como um campo social amplo, devendo o ensino considerar a complexidade na formação profissional(2).

A formação profissional em saúde mental é um processo em constante construção, sendo um tema frequentemente debatido com o intuito de criar estratégias e desenvolver ações capazes de qualificar profissionais para uma prática diferenciada, que tenha o sujeito como seu principal foco de ação e que seja mais condizente com os princípios do Sistema Único de Saúde - SUS ${ }^{(3)}$.

Nas últimas décadas, pesquisas realizadas por economistas, psicólogos e educadores revelam que competências e habilidades como perseverança, autonomia e curiosidade são tão importantes quanto as habilidades cognitivas para a obtenção de bons resultados em diversas esferas do bem-estar individual e coletivo, como educação, renda e saúde. Para a construção de práticas mais efetivas, é irrefutável promover a dialogicidade do ensino teórico-prático com os saberes advindos das competências afetivas, emocionais e criativas que, quando combinadas, resultam em um processo de cuidado mais humanizado e eficaz ${ }^{(4)}$. Mas um aspecto muito importante presente na sociedade em relação à pessoa portadora de sofrimento psíquico, o estigma da loucura, compromete a aproximação e a interação social com essas pessoas, influenciando também os estudantes de enfermagem. Estudos $^{(6-7)}$ realizados no âmbito do ensino superior revelam a presença de estigma acentuado nos estudantes de saúde e evidenciam maior estereótipo face à perigosidade e imprevisibilidade, comparativamente aos outros estudantes.

Autores $^{(8)}$ destacam que a negatividade apontada para esse sujeito não só afeta o interesse em atuar na área de enfermagem psiquiátrica como o próprio processo de ensino-aprendizagem de cuidar em saúde mental. Este desafio fica ainda mais problemático quando se trata de preparar os novos profissionais de enfermagem para o cuidado em diferentes cenários de atenção psicossocial em saúde mental.

Nosso interesse nesse estudo, diante das principais perspectivas teóricas e práticas, a partir das quais se analisa a necessidade de mudança no ensino de saúde mental, volta-se para a interação do estudante de enfermagem com a pessoa portadora de sofrimento psíquico nos novos espaços de atenção psicossocial. Nesse sentido, delineamos como objetivo desse artigo analisar as emoções do estudante de enfermagem diante da iminência do estabelecimento da relação terapêutica com o usuário do CAPS e levantar a seguinte hipótese para esta questão: $O$ desenvolvimento do ensino de enfermagem nas disciplinas teórico-práticas dos Cursos de Graduação em Enfermagem é ainda insuficiente para o enfermeiro atender as demandas de cuidado exigidas na Atenção Psicossocial?

\section{METODOLOGIA}

Trata-se de um estudo qualitativo, na perspectiva da abordagem Sociopoética, realizado no ano de 2019, com 21 alunos do $6^{\circ}$ período do Curso de Enfermagem na Escola de Enfermagem Aurora de Afonso Costa (EEAAC) da Universidade Federal Fluminense (UFF), matriculados na disciplina "Concepções, Saberes e Práticas no Cuidar em Saúde Mental." Os critérios de exclusão foram: alunos com matrícula trancada ou em licença médica no período da produção de dados.

Para aplicação da sociopoética ao estudo, nos valemos da produção de dados em grupo-pesquisador, considerando a subjetividade, a sensibilidade, a criatividade e a relação com o corpo no processo de pesquisa, conforme preconiza Gauthier ${ }^{(9)}$.

Nesse estudo a produção de dados deu-se através de experimentação estética utilizando-se a técnica dos sentidos com "A Caixa do Inesperado", técnica inspirada no estudo desenvolvido por Fonseca ${ }^{(10)}$. Nessa técnica, caixas fechadas com materiais desconhecidos pelos participantes são colocadas sobre uma mesa, devendo os mesmos tocar os objetos em seu interior estando de olhos vendados. Todas as caixas estavam internamente forradas por plástico e continham, individualmente, um objeto/material diferente. Foram usadas: terra, chaves, slime, moedas e pedras polidas. A sexta caixa continha somente o plástico que forrava seu interior.

A experimentação iniciou-se com a apresentação da pesquisadora, do propósito da pesquisa a ser realizada e assinatura do Termo de Consentimento Livre e Esclarecido (TCLE). Em, seguida os participantes foram vendados, tendo início o relaxamento através de uma música tranquila, com sons da natureza. Foi solicitado ao grupo que, ao relaxar, apropriassem-se à percepção de seus corpos. Após relaxamento, os co-pesquisadores foram levados - ainda vendados - pelos facilitadores a 3 caixas para que tocassem seu conteúdo. Foi entregue a cada participante uma folha de papel dobrada em três partes, para que os mesmos descrevessem as sensações/percepções/ afetos sentidos ao manuseio dos objetos/ elementos contidos nas caixas, relacionando-os ao cuidado da pessoa portadora de sofrimento psíquico em serviços de atenção psicossocial.

Após a experimentação foi realizado um momento onde o grupo-pesquisador produziu a escrita desses afetos sentidos. A escrita foi feita de forma anônima. Após a produção de dados na forma escrita, o 
grupo-pesquisador relatou verbalmente sua experiência, sendo essa etapa da pesquisa considerada para contra-análise.

O estudo obedeceu à Resolução n. ${ }^{\circ}$ 466/12 do Conselho Nacional de Saúde (CNS), sendo aprovado pelo Comitê de Ética em Pesquisa da Faculdade de Medicina da Universidade Federal Fluminense (CEP/FMUFF), n. ${ }^{\circ}$ 2.386.997.
RESULTADOS

Durante a experimentação estética, o tato foi utilizado como agente fomentador dos sentidos. Através do toque com as mãos, os co-pesquisadores deveriam descrever as sensações/percepções/afetos sentidos ao manuseio dos objetos/elementos contidos nas caixas, relacionan- do-os ao cuidado da pessoa portadora de sofrimento psíquico em serviços de atenção psicossocial. Foi atribuído a cada co-pesquisador o nome de uma flor, conforme observado na transcrição dos relatos.

A seguir, são apresentados alguns depoimentos considerados significativos:

Foram relatadas diversas sensações, entre as quais: felicidade, tristeza, medo,

Quadro 1. Depoimentos resultantes da experimentação estética. Niterói, RJ, Brasil, 2019

\section{CO-PESQUI- SADORES}

\section{RELATOS SOBRE AS PERCEPÇÕES DAS CAIXAS}

"Moedas. Sensação de frio, me fez refletir sobre o quanto se investe na saúde mental. 0 frio me retoma ao desconhecido." Caixa 2: Areia. "Sensação de incômodo, não há como tocar na areia e uma parte dela não ficar em você. Inúmeros grãos lembram inúmeras

Verbena possibilidades, um grão contribui com o todo, faz parte do todo e é igual a todos outros (em sua constituição)." Caixa 3: "Amoeba? Sensação de estranheza, coisas que não sabemos lidar, mas podemos nos aprofundar e entender mais sobre, deixar de lado pré-conceitos."

"Despertou um sentimento de nostalgia. Parecia terra, areia e pequenos pedaços de grama com pedrinhas. Lembrei de como era bom brincar na rua quando criança." Caixa (Cx) 2: "O slime com as bolinhas de isopor me deixou com nervoso. Fiquei com vontade

Girassol de brincar." Cx 3: "Saudades, as chaves me fizeram sentir saudades da casa da minha mãe, em minha cidade natal. Acredito que esse contato pela inconsistência das coisas e pessoas é de suma importância. Principalmente ao lidar com o atendimento psicossocial na saúde."

Lírio

"Na Primeira caixa me senti vazio, sem nenhuma emoção e com medo do que estava ali." "Na segunda caixa me senti um pouco mais confiante e sem medo." "Na terceira caixa me senti tranquila e mais preenchida, tocando mais, tendo mais segurança."

Amarilis "Estranheza. Receio, medo do que ia sentir, insegurança. Cx 2: Curiosidade e ao sentar senti minhas pernas e meus braços vibrando. Cx 3: Vontade de rir e ao sentar meu corpo vibra como se estivesse sentindo uma alma entrando em mim.

"Algo que remete a pegajoso, sensação de estranheza. Quando algo não é conhecido e causa estranhamento." Cx 2: "Algo que

Gérbera remete a sensação de leveza, sensação boa ao toque e conforto. Remete a um sentimento também de algo raso, que é incansável." Cx 3: "Algo que remete à frieza, sensação que a princípio é desagradável. Remete ao sentimento que provoca distanciamento."

Antúrio

"Moedas Os pacientes estavam em um quarto frio, todos no chão e amontoados." Cx 2: "Caixa vazia, com o plástico. Um quarto de hospital vazio, os pacientes não estavam mais." Caixa 3: "Areia- Os pacientes foram para a praia. Experimentei uma sensação de liberdade."

"Na primeira caixa pude sentir algo que me remeteu a algo sólido, porém sem conexão, um sentimento de que as coisas estavam fragmentadas." Cx 2: "A segunda caixa trouxe um sentimento de estranheza, de receio, de frieza, que levou a pensar em situações onde somos frios e incapazes de assumir uma postura de aproximação e acolhimento que os pacientes poderiam necessitar." "A terceira caixa foi, para mim, a que mais disse algo que eu pude trazer para a minha realidade. Senti o peso que o dinheiro exerce sobre todos nós e como ele pode ser um fator influenciador em todo o tratamento de um paciente."

"As chaves remetem a sensação dupla de liberdade e aprisionamento, uma vez que o mesmo material pode causar o aprisionamento e construir a barreira e esse mesmo material pode libertar de uma barreira, como nas algemas, nas prisões, nas casas. 0 mesmo material é capaz de ter e transportar a pessoa à duas realidades diferentes." Cx 2: "As pedras remetem a dureza e força, para desfragmentá-la é preciso de força, pela maneira que a mesma se encontra é possível remeter a sensação de dureza e força que é preciso para lidar com a vida. Onde uma sensação é capaz de suportar a outra (a força supera a dureza), sendo assim nos obstáculos da vida." Cx 3: "A gelatina remete à mutação, como um mesmo material pode ser modelado a formas distintas, mas a essência (matéria prima) é a mesma. Mostrando a capacidade do ser se apresentar de formas diferentes, mas com a mesma essência, do ser poder aparentar maneiras mas a matéria é a mesma."

"Primeiro senti um estranhamento e angústia em tocar em areia com pequenas pedras, que grudavam nas mãos. Pude relacionar com a solidão muitas vezes sentida por indivíduos que sofrem psiquicamente." Cx 2: "Em segundo lugar, ao tocar em moedas, senti tristeza por pensar na possibilidade de relacionar à Saúde Mental. A partir disso, veio à minha mente em como muitas vezes esses

Miosótis pacientes são negligenciados pois não apresentam muito impacto na economia do país. A maioria dos indivíduos em sofrimento mental trabalham ou estudam e produzem economicamente. Por isto, estas condições ainda são negligenciadas e não recebem a devida atenção das autoridades e não recebem investimento financeiro." Cx 3: "Por último, ao tocar as chaves senti relaxamento pois imaginei em soluções e conforto para pacientes. Em minha interpretação, as chaves são o acompanhamento profissional da saúde e o apoio e suporte de familiares e amigos, essenciais para melhora e alívio do sofrimento psíquico." 
"Continha dinheiro. Ao tocar nessa caixa, eu pensei no poder que ele traz. Hoje as pessoas não são mais vistas pela essência e sim pelo poder aquisitivo. Quando lidamos com os pacientes precisamos pensar em que realidade ele está inserido para saber o tipo de Tulipa tratamento e de demanda." Cx 2: Continha areia. De imediato me trouxe desconforto, porque é uma coisa que me incomoda muito, mas ao longo eu pensei em férias, alívio. Temos que pensar nos incômodos e no que faz a pessoa relaxar. Cx 3: "Tinha chaves. Pensei nas conquistas e na questão de moradia e na localidade onde a pessoa vive. Essa caixa me trouxe um sentimento de sonho, porque sonho em ter a casa própria."

"O sentimento foi de vazio, de algo faltando, mesmo tendo uma folha plástica. Relacionado ao paciente psíquico, senti necessidade de 'preencher aquele espaço, com algo a cooperar ao cuidado daquele paciente." Cx 2: Senti novidade, tranquilidade e preenchimento. Fiquei um tempo analisando os formatos das pedras. Me lembra um paciente com várias personalidades, pode ser que tenha um sofrimento psíquico, mas meio que seria a essência dele. Várias caixinhas de vários formatos dando o formato de uma pessoa.

Margarida A pessoa é agradável, tem um problema mental que precisa ser analisado." Cx 3: "Senti nojo, repulsa, nem quis colocar a mão por muito tempo. Senti um sentimento de desafio. Pacientes dificeis que talvez produzam um sentimento desse nível são bem comuns. Os agressivos (verbalmente ou fisicamente), os que nem tomam banho etc. Esses são um desafio de cuidado e analisando o contexto, deve-se "colocar mais a mão e suportar", a fim de conseguir mecanismos de cuidar daquele paciente e entendê-lo."

surpresa, raiva e nojo, além de uma ambiguidade de sensações, nem sempre expressas de forma clara. Por vezes, a ambiguidade se fez patente e foi nítida a dificuldade de relatar e descrever as emoções e sentimentos na forma escrita, aparecendo meIhor o que o corpo fala, e se apresenta de maneira marcante para expressar conteúdos velados dentro de si mesmo.

A caixa do inesperado deu lugar para a expectativa do contato com o imprevisível no campo da atenção psicossocial. Assim como a caixa provocou ansiedade e alegria no estudante durante o processo de explorar um objeto nela contido, ela também demonstrou poder ser um veículo ou se colocar como dispositivo para auxiliar o portador de transtorno psíquico a expressar seus sentimentos.

\section{DISCUSSÃO}

Com base na discussão produzida no grupo-pesquisador acerca das emoções relacionadas à interação com os usuários do CAPS, produzidas a partir das sensações provocadas pelos elementos surpresa presentes na caixa do inesperado, verificou-se que é marcante a presença do reducionismo das explicações meramente duais pela via da racionalidade teoria/prática certo e errado, limpo/sujo, bom ou ruim, entre outros. Isso se expressa quando um estudante fez referência a um sentimento de decepção, porque a prática não seria igual à teoria do que se aprende nas disciplinas durante os espaços de formação em saúde de modo geral.

Essa é uma visão dual por parte do acadêmico, como se tudo se tratasse do sim ou não: a prática deve atender à teoria (sim ou não, sem outra possibilidade). Trata-se de uma visão reducionista da relação teoria/prática, como se a prática tivesse sempre que atender às expectativas criadas pela teoria. Tal reducionismo foi discutido por Dejours $^{(11)}$, na relação entre uma tarefa e um trabalho efetivamente realizado. $\mathrm{O}$ autor destaca a "infidelidade do meio" como aspecto fundamental de toda prática baseada em uma teoria. É a prática que existe em completude todo mundo da vida como ela é, não a teoria.

Mas esta realidade não existe com vertentes em relações totalmente lineares e, portanto, não podem ser analisadas de forma linear. A realidade da formação em saúde não está restrita a somente estas duas esferas (teoria e prática), porque elas não são tudo. Há infinitas variáveis entre a experiência da teoria e a experiência da prática, tantas quantas forem necessárias para que se contemple cada tipo de encontro no cuidado e que, por isso, são fabricadas em ato, no próprio encontro com o outro.

A experimentação fez com que o estudante se encontrasse com sentimentos inaceitáveis, isto é, a atividade produziu afetos que o estudante considera que precisa apagar. Trata-se daqui- lo que sentiu e que gostaria de suprimir de dentro de si por ser algo moralmente inadequado aos olhos externos, e que, por isso, ele considera que não pode aceitar. Isso se mostrou claramente quando uma caixa provocou estranheza e repulsa no estudante que, em seguida, considerou que, para cuidar de portadores de transtorno psíquico ele precisaria apagar estes sentimentos (ou, mesmo, não os ter), como se o cuidado precisasse ser estéril de afetos.

Nota-se que a experimentação instala uma tensão entre o corpo sensível e o corpo pensamento. Quando o estudante se vê diante de repulsa, quer se autocorrigir, em vez de problematizar o que sente. A razão em conflito com a emoção é um dos principais desafios no campo da formação em saúde. A falácia da neutralidade dá um ar de resolução, mas a angústia permanece. Aquele que cuida, o faz com seu corpo pensamento e seu corpo sensível, mas o processo hegemônico de formação e trabalho em saúde tenta, equivocadamente, apagar ou negar as emoções nele contidas. Quem cuida não pode, simplesmente, fugir dele mesmo, pois o seu corpo sensível também está presente durante a sua formação e durante seus processos de trabalho. A diferença é que, quando se aceita que as emoções estão presentes nesses processos, pode-se tentar fazer delas instrumento de trabalho, em vez de algo que domina e torna o profissio- 
nal como uma marionete daquilo que não se quer enxergar.

Nesse sentido, o uso de experimentações nos processos de ensino-aprendizagem legitima uma formação que não negue o corpo-sensível e faça dele instrumento de trabalho assim como é o corpo-pensamento.

Por outra via, a experimentação permite a abertura de linhas de fuga para o novo: chaves para abrirem as portas para novas explicações clínicas, estimuladas pela curiosidade tocada pelo contato das chaves. A chave está no senso comum como algo relativo às respostas, mas, fora do campo estritamente racional, ela pode ser, ao invés de resposta, uma pergunta, como foi o caso do encontro deste objeto que abriu para perguntas, provocar novos porquês, duvidar das explicações inicialmente mais óbvias. Ao invés das dualidades reducionistas que opõem elementos de uma relação, as linhas de fuga apontam para novos modos de experimentar os contatos entre esses elementos. Numa relação de cuidado que priorize a vida, em vez da reprodução de modelos, teoria e prática (e todos os pares que surgiram no processo) poderiam se encontrar de modo a se potencializarem mutuamente ${ }^{(12,13)}$.
Outra linha de fuga valiosa nesta experimentação foi a produção de euforia e de ansiedade no estudante durante a expectativa do contato com a caixa, misturado com um sentimento de alegria. Isso provocou no estudante o lugar da alteridade, como se estivesse diante de um paciente com transtorno psíquico precisando encorajá-lo a expressar seus sentimentos.

Ainda fora percebido uma visão manicomial nos co-pesquisadores, embora a Reforma Psiquiátrica tenha tido início no final da década de 70, em maioria, os depoimentos se concentram em experiências e em vivências com o a pessoa em sofrimento psíquico não atrelada ao atendimento territorial do CAPS, ambulatórios, Estratégia de Saúde da Família (ESF) ou qualquer outro dispositivo de assistência pertencentes a Rede de Atenção Psicossocial. Da mesma maneira, em nenhum depoimento houve menção à equipe multiprofissional, levando a compreender que os alunos não enxergam a potência do trabalho de matriciamento, vital para a promoção do tratamento/ acompanhamento do usuário na Atenção Psicossocial. Foi observado ainda que nenhum co-pesquisador fez referência ao portador de sofrimento psíquico perten- cente à classe média alta/classe $\mathrm{A}$. Todos os relatos remeteram a pessoas de baixa renda ou pobreza extrema/miséria.

\section{CONCLUSÃO}

A experimentação estética objetivava que os co-pesquisadores relacionassem as sensações/percepções/afetos à interação com a pessoa portadora de sofrimento psíquico na atenção psicossocial no CAPS. Dos 21 participantes, apenas 10 fizeram menção à atenção psicossocial e, ainda assim, não conseguiram relacionar as três caixas ao tema solicitado. Todos os participantes foram afetados pelos objetos contidos nas caixas, o que demonstrou grande necessidade e urgência para falarem sobre suas próprias afetações e sentimentos. Os estudantes apresentaram uma visão hospitalocêntrica, além de falas estigmatizadas face ao portador de sofrimento psíquico. Diante do exposto, constata-se a experimentação estética da Sociopoética como potente geradora de mobilizações de afetos e emoções e de como este método pode ser utilizado como contributo no processo de ensino-aprendizagem na enfermagem em Saúde Mental.

\section{Referências}

1. Fortes FLS, Peres MAA, Santos TCF, Martins GCS, Montenegro HRA, Almeida Filho AJ. Enfermeiro em saúde mental: concepções sobre qualificação profissional em um Centro de Atenção Psicossocial. Rev. Rene [Internet]. 2017 nov-dez [acesso em 19 jul 2019]; 18(6):763-70. Disponível em: http://periodicos. ufc.br/rene/article/view/31086.

2. Cortes JM, Kantorski LP, Barros S, Antonacci MH, Chiavagatti FG, Willrich JQ. Saberes e fazeres que integram o ensino de enfermagem psiquiátrica na perspectiva de enfermeiros docentes. Revista Portuguesa de Enfermagem de Saúde Mental [Internet]. 2014 [acesso em 13 mai 2019]; 12:34-42. Disponivel em: http://www.scielo.mec.pt/scielo.php?script=sci_arttext\&pi$\mathrm{d}=\mathrm{S} 1647-21602014000300005 \& \operatorname{lng}=\mathrm{pt} \& \mathrm{nrm}=$ iso.

3. Rosa $M$, et al. Inovações na formação em saúde: o programa de educação pelo trabalho - Saúde Mental. Revista Portuguesa de Enfermagem de Saúde Mental [Internet]. 2016 out [acesso em 19 jul 2019]; 4(39). Disponivel em: http://www.scielo.mec.pt/scielo.php?script=sci_arttext\&pi$d=S 1647-21602016000400006$.

4. Santos D, Primi R. Desenvolvimento Socioemocional e Aprendizado Escolar: Uma Proposta de Mensuração Para Apoiar Políticas Públicas. Resultados preliminares do Projeto de medição de competências socioemocionais no Rio de Janeiro. 2014. Secretaria do Estado do Rio de Janeiro, Instituto Ayrton Senna, OCDE - Des Politiques Meilleures Pour Une Vie Meilleure.

5. Amarante PDC. 0 homem e a serpente: outras histórias para a loucura e a psiquiatria. Rio de Janeiro: Fiocruz; 2016.

6. Gil I. Crenças e atitudes dos estudantes de enfermagem acerca das doenças e doentes mentais: Impacto do ensino clínico de enfermagem de saúde mental e psiquiatria. Dissertação de Mestrado, Faculdade de Medicina da Universidade de Coimbra, Portugal, 2010.

7. Querido A, Tomás C, Carvalho D. 0 estigma face à doença mental nos estudantes de saúde. Revista Portuguesa de Enfermagem de Saúde Mental [Internet]. 2016 abr [acesso em 19 jul 2019]; 3(67). Disponível em: http://www.scielo.mec.pt/scielo.php?script=sci_arttext\&pid=S1647-21602016000200012. 8. Carvalho JCM, Tavares CMM. Nursing students? Depiction of mental disorder. The Journal of Mental Health Training, Education and Practice [Internet]. 2017 [acesso em 19 jul 2019]; 12:323-330. Disponível em: https://www.emerald.com/insight/content/doi/10.1108/JMHTEP-12-2016-0057/full/html.

9. Gauthier J. 0 oco do vento: metodologia da pesquisa sociopoética e estudos transculturais. Curitiba: CRV; 2012.

10. Fonseca PIMN. 0 autoconhecimento e sua multidimensionalidade aplicada a equipes de transplantes. Tese doutorado, Universidade Federal Fluminense, 2017.

11. Dejours C. A banalização da injustiça social. Rio de Janeiro: FGV; 2011.

12. Espinosa B. Ética demonstrada à maneira dos geômetras. Lisboa: Olho d'água; 2002.

13. Machado R. Deleuze, a arte e a filosofia. Rio de Janeiro: Zahar; 2009. 